\title{
Las ciudades checas desde el exilio: Milan Kundera
}

\author{
Rocío Peñalta Catalán \\ Departamento de Filología Románica, Filología Eslava y Lingüística General \\ Universidad Complutense de Madrid \\ rociopenalta@filol.ucm.es
}

\section{RESUMEN}

En este artículo se analiza la imagen que ofrece Milan Kundera de las ciudades checas en dos novelas, La broma publicada en 1965 y El libro de la risa y el olvido, que provocó la revocación de la ciudadanía checa del autor en 1981. El novelista presenta unas ciudades oscuras, tristes, sucias. Esta visión pesimista de su país natal se opone a la opinión que le merecen las ciudades occidentales, con las que establece un claro contraste. En ambas novelas se reflejan acontecimientos históricos, vivencias personales y opiniones subjetivas del autor exiliado.

Palabras clave: Milan Kundera, exilio, ciudades checas, La broma, Libro de la risa y el olvido.

The Czech cities from the exile: Milan Kundera

\begin{abstract}
In this article we analyze the image that Milan Kundera offers of the Czech cities in two novels, The Joke, published in 1965 and The Book of Laughter and Forgetting, whose publication cost him the loss of the Czech citizenship in 1981. The author describes dark, sad and dirty cities. This pessimistic vision of his homeland is opposite to his opinion on the Western cities, with which a clear contrast is established. In both novels historic events, personal livings and subjective opinions of the exiled author are reflected.
\end{abstract}

Key words: Milan Kundera, exile, Czech cities, The Joke, The Book of Laughter and Forgetting.

Milan Kundera es uno de los grandes exiliados; su nombre es uno de los que primero vienen a la mente cuando se habla de literatura del exilio (Muñiz-Huberman 
1999: 68). Cuando en 1975 Kundera abandonó Checoslovaquia, eligió Francia como país de residencia y el francés como lengua literaria. Sin embargo, a pesar de la distancia física y emocional, Praga y otras ciudades checas no dejan de estar presentes en su obra.

En general, la visión que Milan Kundera ofrece en sus novelas de los paisajes checos -especialmente cuando se trata de paisajes urbanos- es negativa y pesimista. Sólo algunos panoramas naturales son descritos de manera positiva. Las ciudades checas son feas, sucias e inhumanas. Y, en muchos casos, los sentimientos de los personajes se asocian a este paisaje. La perspectiva cambia, sin embargo, cuando se trata de ciudades occidentales.

Es curioso el hecho de que Milan Kundera muestre esta visión tan negativa de su país de origen incluso años antes de exiliarse. Ya en su primera novela, La broma, publicada en 1965, las ciudades checas aparecen caracterizadas de esta manera tan negativa. Sin embargo, Kundera no dejó el país hasta diez años más tarde.

La época y las circunstancias vitales en que fueron escritas estas obras son fundamentales para entender algunos aspectos de su literatura. En este caso, centraremos nuestro análisis fundamentalmente en dos novelas, La broma y El libro de la risa y el olvido, ambas importantes por diferentes motivos y de las que se pueden extraer fácilmente detalles del contexto de su escritura.

La broma es la primera novela publicada por Milan Kundera. Es interesante su estudio, por una parte, porque en ella el autor introduce numerosas referencias al contexto histórico, político y cultural de la época en la que se desarrolla la narración -desde la "liberación" de 1948 hasta el presente de la escritura, 1965-y, por otra parte, porque contiene algunos datos autobiográficos que permiten identificar las vivencias y las ideas de los personajes con las del propio Kundera.

En ella, el protagonista, llamado Ludvik Jahn -Ludvik era también el nombre del padre de Kundera-, vuelve a su ciudad natal para vengarse de un amigo de su juventud, al que acusa de haber arruinado su vida. Estando en la universidad, Ludvik envió una postal a una chica de la que estaba enamorado y, para impresionarla, escribió algunas frases que se oponían a los ideales comunistas y se mostraban favorables al trotskismo. Ludvik es acusado de subversión y, a pesar de que intenta explicar por todos los medios que se trataba de una broma, es expulsado del partido comunista, en el cual militaba; obligado a abandonar sus estudios universitarios, y condenado a cumplir el servicio militar con galones negros, lo que implicaba trabajar en las minas durante una cantidad indefinida de años. Una vez cumplida la pena y relativamente rehabilitado, decide regresar a su pasado y castigar a aquellos que le traicionaron.

Es a través de las voces de otros personajes como el lector puede reconstruir la historia, acceder a distintas perspectivas de los acontecimientos narrados por el protagonista y descubrir en qué consiste la venganza: Ludvik pretende seducir a la esposa de Pavel Zemanek, uno de los líderes del movimiento comunista universitario que presidió el tribunal que le condenó a abandonar el partido y la universidad, con el fin de humillar a éste último. Sin embargo, hace ya mucho tiempo que Zemanek y Helena, su mujer, viven separados; por lo que lo único que consigue Ludvik es que Helena se enamore locamente de él y, a causa del rechazo de éste, ella intente suicidarse. La venganza se vuelve así en su contra. 
La segunda de las obras que nos interesan, El libro de la risa y el olvido, es importante porque supuso la revocación de la ciudadanía checa de Milan Kundera en 1981. Curiosamente, ese mismo año -1981- Kundera era premiado en Estados Unidos por el conjunto de su obra con el Commonwealth Award, galardón recibido ex aequo por el dramaturgo norteamericano Tennessee Williams. Sin embargo, cuando se produce este hecho, Kundera llevaba seis años viviendo en Francia (Bloom 2003: 148).

Aunque ya había sido expulsado del partido comunista, en cuyas filas militaba, en dos ocasiones -la primera en 1948, después de la toma del poder por parte de los comunistas en febrero de ese año, y por segunda vez, y ya definitivamente, en 1970 y a pesar de que sus libros habían sido prohibidos a raíz de la ocupación soviética de 1968 y de que había perdido su empleo, Milan Kundera no partió al exilio hasta 1975 (Nuñez 2007).

Seis años después, como ya hemos señalado, y con motivo de la publicación de esta obra, el gobierno de Checoslovaquia decide negarle la ciudadanía al escritor. El libro de la risa y el olvido es una obra compleja.

Todo este libro es una novela en forma de variaciones. Las distintas secciones van una tras otra como distintos trozos de un camino que va hacia adentro del tema, adentro de la idea, adentro de una sola y única situación, cuya comprensión se me pierde allí donde ya no alcanza la vista. Es una novela sobre Tamina y en el momento en que Tamina desaparece de la escena, es una novela para Tamina. Ella es el personaje principal y el principal espectador y todas las demás historias son variaciones de su historia y se reúnen en su vida como en un espejo. (Kundera 2003: 247)

Aunque el autor lo define como una novela, se trata, más bien, de un conjunto de textos en el que se mezclan las voces de los personajes, de los narradores y del propio autor, que cuenta hechos de su pasado. Lo que dota de coherencia al libro es la presencia reiterada de ciertos personajes y temas. Como el título indica -y citando a Kundera- El libro de la risa y el olvido "es una novela sobre la risa y el olvido, sobre el olvido y Praga, sobre Praga y los ángeles" (Kundera 2003: 247).

En esta obra encontramos más elementos claramente autobiográficos que en $\mathrm{La}$ broma. Algunos capítulos no son otra cosa que los recuerdos de Milan Kundera acerca de la ocupación soviética de Praga, de la muerte de su padre o de su salida del país.

Las circunstancias en el panorama europeo de esos años son complejas, y no todos los acontecimientos fueron favorables al novelista checo. Esto explica que su visión negativa -especialmente en el caso de La broma- no se limite a los espacios, como decíamos, sino que afecte también al tiempo. Y lo hace en dos sentidos. En primer lugar, se refiere al tiempo histórico, al contexto en que tienen lugar los acontecimientos narrados en la novela. En segundo lugar, esta visión negativa define también la etapa vital que el personaje principal y el propio autor de La broma vivían en esos primeros años de la narración.

La época en la que se desarrolla el argumento de La broma, entre febrero de 1948 y el presente de la narración, los primeros años de la década de 1960, es nega- 
tiva en todos sus aspectos, desde lo más banal hasta lo más trascendental. Ludvik Jahn, protagonista de la novela, la califica de inelegante -"los dos llevábamos unos largos impermeables, sí, largos, hasta un poco más abajo de la rodilla, tal como en aquella época (una época totalmente inelegante) solían llevarse" (Kundera 1984: 49)-; considera que es una época que no entiende el humor -"el humor era algo que le caía mal [...] al espíritu de nuestro tiempo" (Kundera 1984: 37)-; una época falsa, en la que las ceremonias no son más que una representación teatral que carece de sentido, donde es más importante aparentar que ser; donde incluso las convicciones políticas no son más que una máscara, muy necesaria para conservar cierta posición social y los privilegios derivados de ella (y no verse despojado de derechos fundamentales).

Por otra parte, al aludir a la etapa vital en la que se encontraban el propio Milan Kundera y su personaje, Ludvik Jahn, en la época en la que comienza la narración, es decir, a finales de la década de 1940 y principios de los años 50, nos referimos a su juventud. El narrador mantiene una opinión muy negativa con respecto a los jóvenes, a los que describe como inmaduros, irreflexivos y egocéntricos. El joven es egoísta, y no piensa en los otros más que cómo reflejo de él mismo, como instrumentos para satisfacer sus necesidades:

Me invadió una ola de rabia contra mí mismo, contra la edad que entonces tenía, contra la estúpida edad lírica en la que el hombre es para sí mismo un misterio demasiado grande como para que pueda dedicarse a los misterios que están fuera de él, la edad en la que los demás (aun los más queridos) no son para él más que espejos móviles en los que ve, asombrado, sus propios sentimientos, su propia emoción, su propia valía. (Kundera 1984: 263)

Los jóvenes actúan como los adultos sin estar preparados para ello; interpretan el papel que consideran más apropiado en cada situación, o que mejor les sienta, como si fuesen actores, sin saber quiénes son en realidad.

No es culpa de los jóvenes el que actúen; no están hechos del todo, pero se encuentran en un mundo que ya está hecho y tienen que actuar como hechos. Por eso utilizan rápidamente las formas, los modelos y los guiones que más les gustan, que se llevan, que les sientan bien $-\mathrm{y}$ actúan. [...] La juventud es terrible: es un escenario por el cual, calzados con altos coturnos y vistiendo los más diversos disfraces, los niños andan y pronuncian palabras aprendidas, que comprenden sólo a medias, pero a las que se entregan con fanatismo. Y la historia es terrible porque con frecuencia se convierte en un escenario para inmaduros; un escenario para el jovencito Nerón, un escenario para el jovencito Napoleón, un escenario para masas fanatizadas de niños, cuyas pasiones copiadas y cuyos papeles primitivos se convierten de repente en una realidad catastróficamente real. (Kundera 1984: 99-100)

Era serio, entusiasta y convencido en las reuniones; provocativo y crítico con los amigos más cercanos; era cínico y artificialmente ingenioso con Marketa; y cuando estaba solo (y pensaba en Marketa) era indeciso y tembloroso como un escolar. [...] Todas aquellas caras eran verdaderas. No tenía, como los hipócritas, una cara verdadera y unas caras falsas. Tenía varias caras porque era joven y yo 
mismo no sabía quién era y quién quería ser. (Sin embargo, la desproporción entre todas aquellas caras me asustaba; no había llegado a asumir por completo ninguna de ellas y me movía detrás de ellas con la torpeza de un ciego). (Kundera 1984: 39)

Esta visión negativa se debe, fundamentalmente, a que durante su juventud el protagonista de la novela cometió una serie de errores que arruinaron su vida, alejándole de sus estudios en la universidad y del partido comunista, y convirtiéndole en un enemigo a los ojos del gobierno.

Si durante su juventud Ludvik Jahn apoyó con entusiasmo el comunismo, años después, en su madurez, su opinión acerca de las ideologías y los partidos políticos ha cambiado sensiblemente. La época en que asistía a la universidad, en que luchaba por los ideales comunistas, le resulta ahora extraña, y comprueba que aquellas circunstancias sociales e históricas dieron origen a su generación, que, desde la perspectiva de los que ahora son jóvenes, se presenta como un todo monolítico, donde no existe la creatividad ni las ideas propias:

Cuanto más me gustaba la señorita Brozova, más me daba cuenta de que compartía la opinión de sus coetáneos, para quienes yo y los de mi edad somos una masa única e indiferenciada, todos deformados por igual por el mismo argot político incomprensible, con el mismo tipo de pensamiento superpolitizado, con las mismas angustias (que parecen cobardía o miedo), con las mismas extrañas experiencias de quién sabe qué época negra y lejana. (Kundera 1984: 287-288)

Hay que tener en cuenta que en esta época, en 1965, cuando Milan Kundera escribe La broma, ya había sido expulsado por primera vez del partido comunista -en 1948- y aunque luego se reintegrara en su seno y militase hasta 1970, ya podía observar las cosas con cierta distancia, desde una perspectiva diferente (Bloom 2003).

Ludvik no puede más que mostrarse de acuerdo con esta opinión. De manera que Jahn y su antagonista, Pavel Zemanek, el hombre al que acusa de haber arruinado su vida y del que se quiere vengar, no son tan distintos. Es más, la semejanza llega a tal punto que se convierte en identidad:

En ese momento comprendí que la semejanza entre Zemanek y yo no consiste en que Zemanek haya modificado sus opiniones y se haya acercado así a mí, sino que se trata de una semejanza más profunda que afecta a toda nuestra vida: la mirada de la señorita Brozova y de los de su generación nos vuelve semejantes aun allí donde hemos estado furiosamente uno contra otro. Sentí de pronto que si me obligaran (¡me resistiría!) a contar delante de la señorita Brozova la historia de mi expulsión del partido, le parecería demasiado lejana y demasiado literaria ( ¡sí, claro, una historia contada tantas veces en tantas novelas malas!), y que en esa historia seríamos igualmente desagradables Zemanek y yo, mi modo de pensar y el suyo, mi postura y la suya (ambas igualmente monstruosas). (Kundera 1984: 288)

La ansiada venganza pierde así todo su sentido. 
Si Ludvik Jahn renegaba de su juventud y señalaba los errores que se cometen en esos años, su enemigo, el triunfador Pavel Zemanek, defiende sin embargo a los jóvenes:

[...] Y así me enteré de que Zemanek es uno de los profesores más populares de la facultad, que los alumnos lo adoran precisamente por los mismos motivos por los que les disgusta la conducta de la dirección de la escuela: porque dice siempre lo que piensa, tiene coraje y defiende siempre a la juventud. [...] que incluso casi lo habían querido echar porque en sus clases no se atenía a los programa anticuados y rígidos y quería que los jóvenes conociesen todo lo que sucedía en la filosofía moderna (según parece lo acusaron por eso de pretender introducir "la ideología del enemigo"); que había salvado a un alumno al que querían expulsar de la escuela por una chiquillada: una discusión con un policía a la que el rector (enemigo de Zemanek) calificaba de infracción política; que más tarde los alumnos habían organizado una votación para elegir al profesor más popular de la escuela y había ganado él. (Kundera 1984: 283)

En la segunda obra de Milan Kundera que vamos a comentar, El libro de la risa y el olvido, también está presente, aunque en menor medida, esta opinión contraria a la juventud, a la juventud propia: los personajes detestan su propio pasado.

[...] Zdena era sólo un retrato mágico contra el que [él mismo] pretendía disparar para destruir en él su propia aborrecida juventud. (Kundera 2003: 26)

Todo lo absurdo, ridículo y pueril de su viaje se le viene encima. No lo había llevado hasta allí ningún propósito o un interés práctico, sino tan sólo un deseo invencible. El deseo de llegar con la mano hasta muy lejos en el pasado y pegar un puñetazo. El deseo de apuñalar la imagen de su juventud. (Kundera 2003: 40)

Y parece que este rechazo no es privativo del autor y sus personajes, sino que es un sentimiento común a toda su generación:

Los acontecimientos históricos se imitan, por lo general con escaso talento, unos a otros, pero me parece que en Bohemia la historia puso en escena un experimento fuera de lo corriente. Allí no se levantó, siguiendo las viejas recetas, un grupo de personas (una clase, una nación) contra otro, sino que unas personas (una generación) se levantaron contra su propia juventud. Se esforzaron por dar caza y domar a sus propios actos y por poco lo consiguen [...]. (Kundera 2003: 27)

Dejando a un lado el eje temporal, en lo que se refiere a la visión negativa de los espacios, hay que especificar que en el caso de La broma los escenarios urbanos son, fundamentalmente, dos: la ciudad natal del protagonista, cuyo nombre no se especifica, pero que se sitúa en la región checa de Moravia, cerca de Brno -ciudad natal de Milan Kundera, con la cual podríamos equiparar fácilmente-, y Ostrava, una ciudad minero-industrial del noreste de la actual República Checa, capital de la región de Moravia-Silesia, donde Ludvik Jahn, protagonista de la novela, cumple condena trabajando durante años en las minas de carbón, al ser destinado a la división negra del ejército checoslovaco. Praga, la capital, es mencionada en varias ocasiones a lo largo 
de la novela; pero el narrador-protagonista Ludvik no se detiene a describirla detalladamente ni la relaciona con pensamientos o emociones relevantes. Sin embargo, otros personajes, como Helena, por ejemplo, describen Praga como una ciudad florecida, en plena exaltación socialista; Praga es la ciudad de la libertad, de la revolución, del amor. Esta visión contrasta claramente con el pesimismo de Ludvik.

[...] me pareció que era precioso saludar en una plaza de Praga a un líder obrero italiano con una canción revolucionaria italiana, $[. .$.$] poco a poco se nos fueron$ uniendo más y más voces, la gente empezó a entender y la canción lentamente se fue desprendiendo del enorme ruido de la plaza como una mariposa de un inmenso capullo de gritos. [...] la multitud se disolvió y nosotros paseamos varias horas por Praga, por la ciudad florecida. (Kundera 1984: 23)

En el caso de Ostrava, la mencionada visión negativa es lógica, ya que Ludvik asocia esta ciudad a su estancia en el cuartel militar y al trabajo en la mina entre "los negros", división del ejército cuyos miembros tenían prohibido el manejo de armas, ya que habían sido acusados por el partido comunista de mantener una actitud subversiva o poco acorde con las ideas del régimen (Radio Praha 1998).

Ostrava es una ciudad industrial, sucia y contaminada; por eso, en sus descripciones predomina el color negro del humo de las fábricas y del carbón de las minas:

Anduvimos dando vueltas en medio del extraño verano de Ostrava, lleno de hollín, un verano negro en el que por el cielo, en lugar de las blancas nubes, navegaban los carros de carbón colgados de largos cables. [...] nos sentamos en el bosquecillo ralo que está debajo de Petrvald [...]. (Kundera 1984: 85)

Según la descripción que el narrador hace de Ostrava, podríamos señalarla como un no-lugar (Augé 1992): “[...] Ostrava, esa ciudad minera que parece un enorme dormitorio provisional, lleno de casas abandonadas y de calles que llevan al vacío" (Kundera 1984: 35). Esta falta de identidad de la ciudad se manifiesta, por ejemplo, en la ausencia de nombres en los establecimientos:

Me detuve junto a un edificio bastante grande de dos plantas, que tenía en la esquina, colgado en posición vertical, un cartel: CINE. Se me ocurrió hacerme una pregunta totalmente irrelevante, que sólo se le puede ocurrir a alguien que pasea sin rumbo fijo: ¿cómo es posible que junto a la palabra CINE no ponga también el nombre del cine? Me puse a buscarlo, pero en el edificio (que por lo demás no recordaba para nada a una sala de cine) no había ningún otro cartel. [...] vi en el patio vecino, tras una cerca de alambre, a una niña. Le pregunté cómo se llamaba el cine; la niña me miró con sorpresa y dijo que no lo sabía. Me resigné a que el cine no se llamase; a que en aquel destierro ostravense los cines no tuvieran ni para nombre. (Kundera 1984: 75)

Para Ludvik Jahn, Ostrava es la ciudad de la impropiedad:

Me senté en un viejo tranvía de vía estrecha que conectaba los barrios alejados de Ostrava y dejé que me llevara. A la buena de Dios me bajé después del tranvía y 
me volví a subir a otro de otra línea; toda aquella periferia interminable de la ciudad de Ostrava, en la que se mezclan en una extrañísima combinación la fábrica y la naturaleza, el campo con el basural, los bosquecillos con las escombreras, los edificios de pisos con las casas de campo, me atraía y me excitaba de un modo particular; volví a bajarme del tranvía y fui dando un largo paseo: percibía casi con pasión aquel panorama extraño e intentaba desentrañar su espíritu; trataba de encontrar palabras para denominar aquello que le da a este paisaje compuesto de tan diversos elementos una unidad y un orden; pasé junto a una casa idílica, cubierta de hiedra y se me ocurrió que su presencia allí era apropiada precisamente por eso, porque no tenía nada que ver con los descascarillados edificios de pisos que estaban cerca de ella, ni con las siluetas de las torres de extracción de carbón, las chimeneas y los hornos, que formaban su paisaje; atravesé un grupo de casitas baratas que formaban una especie de poblado dentro del poblado y vi a escasa distancia de ellas una villa, que aunque sucia y gris estaba rodeada por un jardín y una verja de hierro; en una esquina del jardín crecía un gran sauce llorón que era una especie de ser extraviado en este paisaje -y sin embargo, me dije, quizás precisamente por eso era apropiada su presencia allí. Estaba excitado por todos estos pequeños descubrimientos de impropiedad, no sólo porque en ellos veía el denominador común de este paisaje, sino sobre todo porque veía en ellos una imagen de mi propio sino, de mi propio destierro en esta ciudad; y por supuesto: el proyectar mi situación personal en la objetividad de toda la ciudad me brindaba una especie de resignación; comprendí que yo era allí inapropiado igual que eran inapropiados el sauce llorón y la casa con la hiedra, igual que eran inapropiadas aquellas calles cortas que conducían al vacío y a ninguna parte, calles hechas de casas que parecía como si hubieran venido cada una de un sitio distinto, era inapropiado allí igual que eran inapropiados -en un paisaje que una vez fue acogedoramente rural- los monstruosos barrios de achatados barracones provisionales y me daba cuenta de que, precisamente porque era inapropiado, debía estar allí, en aquella horrible ciudad de la impropiedad, en una ciudad que ha enlazado, en un desaprensivo abrazo, todo lo que se es ajeno. (Kundera 1984: 73-74)

Es precisamente la falta de coherencia, la diversidad de elementos que conforman los barrios, lo que dota de unidad a la ciudad. Cada edificio, cada calle, cada árbol justifica su presencia allí precisamente por su impropiedad, por la falta de adecuación al entorno. Sólo desde esta perspectiva tiene sentido su propia presencia en la ciudad -como vemos en la cita-; la estancia de Ludvik Jahn en Ostrava es improcedente, puesto que ha sido condenado por error, a causa de una broma mal interpretada, pero cuanto más inadecuado resulta este - en sus palabras- "destierro ostravense" más consciente es de que debe estar allí.

Sin embargo, a pesar de sentirse totalmente ajeno en esa ciudad, el entorno no es tan distinto - al menos desde su punto de vista, si atendemos a sus descripciones- de su ciudad natal. Esa innombrada ciudad morava aparece explícitamente identificada con Ostrava: "Las ciudades tienen la propiedad de hacer unas de espejo de las otras y yo en este escenario (lo conocía desde la infancia y entonces no me decía absolutamente nada) vi de repente a Ostrava" (Kundera 1984: 35). Si Ostrava tiene un cielo negro, manchado de hollín, en su ciudad natal será el río el que aparezca marrón: 
Me detuve en el puente sobre el Morava y miré en el sentido en el que corre el agua. Qué feo es el Morava (un río tan marrón como si por él corriera barro líquido en vez de agua) y qué desolada es su ribera: una calle formada por cinco casas de una sola planta, que no están unidas, sino cada una por su lado, extravagantes y abandonadas; quién sabe si debían haber servido de base para un malecón ostentoso que nunca llegó a realizarse; dos de ellas tienen cerámicas y estucados, angelitos y pequeñas escenas que hoy ya están desconchadas: al ángel le faltan las alas y las escenas están en algunas partes desnudas hasta el ladrillo, de modo que se hacen ininteligibles. Luego termina la calle de las casas abandonadas y ya no hay más que los postes metálicos del tendido eléctrico, el césped y en él unas cuantas ocas a las que se les ha hecho tarde, y luego el campo, un campo sin horizonte, un campo que no llega a ninguna parte, un campo en el que se pierde el barro líquido del río Morava. (Kundera 1984: 35)

Volvemos a encontrar, en esta descripción de la ciudad natal del protagonista, esa impropiedad que caracterizaba a Ostrava, aunque aquí se limita a elementos concretos del paisaje urbano: "cinco casas [...] que no estaban unidas, sino cada una por su lado, extravagantes [...]".

Si en Ostrava, la privación de libertad de Ludvik Jahn resultaba ostensible, por su reclusión en el cuartel, rodeado de vallas metálicas y torres de vigilancia, en su ciudad natal esta reclusión es mucho más sutil y se manifiesta en detalles como los ángeles sin alas que decoran las fachadas de las casas, las calles que terminan y no conducen a ningún lugar, "un campo sin horizonte, un campo que no llega a ninguna parte". Todos estos elementos se relacionan con su falta de elección en el pasado, el irremediable destino al que fue condenado sin que se le diese la posibilidad de defenderse; pero también a los actos que va a llevar a cabo y que determinarán su futuro. La ciudad aparece, por lo tanto, asociada a recuerdos negativos:

Sí, fue aquí, en el momento en que perdí a Lucie, donde en realidad comenzó esa larga época de desesperanza y vacío, en cuya imagen se me convirtió por un momento el turbio escenario periférico de mi ciudad natal [...]. (Kundera 1984: 132)

Así que después de muchos años me encontré otra vez en casa. Estaba en la plaza principal (por la que había pasado infinidad de veces de niño, de muchacho y de joven) y no sentía emoción alguna; por el contrario, pensaba que aquella palza llana, por encima de cuyos tejados sobresale la torre del ayuntamiento (semejante a un soldado con un antiguo casco), tiene el aspecto del patio de un cuartel y que el pasado militar de esta ciudad morava, que sirvió de bastión contra los ataques de húngaros y turcos, había marcado en su rostro un rasgo de fealdad irrevocable.

Después de tantos años, no había nada que me atrajera hacia mi lugar de nacimiento [...]. Pero me engañaba: lo que llamaba desinterés era en realidad rencor [...]. (Kundera 1984: 9)

El paisaje de la ciudad, especialmente de sus afueras y arrabales, es un reflejo de los sentimientos del narrador: 
Por allí pasaba un sendero bordeado a un costado por una tupida hilera de chopos: un estrecho mirador. A su derecha descendía hasta la superficie del río la ribera crecida de hierba y yerbajos y más allá del río se veían en la orilla opuesta depósitos, talleres y patios de pequeñas fábricas; a la izquierda del camino había en primer lugar un extenso basural y luego el campo abierto, claveteado por las construcciones de hierro de los postes del tendido eléctrico. Pasé por encima de todo aquello como si anduviera por una larga pasarela sobre las aguas y si comparo todo ese paisaje a una amplia extensión de agua es porque me venía de allí una sensación de frío y porque iba por aquella arboleda como si me pudiera caer de ella. Y mientras tanto me daba cuenta de que el especial aspecto fantasmagórico del paisaje no era más que una copia de aquello que no había querido recordar tras el encuentro con Lucie; como si los recuerdos reprimidos se trasladaran a todo lo que ahora veía alrededor de mí, al desierto de los campos, los patios y los depósitos, a lo turbio del agua y a aquel frío omnipresente que le daba unidad a todo el escenario. Comprendí que no podía huir de los recuerdos; que estaba rodeado por ellos. (Kundera 1984: 36)

La comparación es explícita, pero no es el único caso que encontramos en el libro. Esta sensación de desolación no se limita, como podría pensarse en un principio, a las afueras y las zonas deshabitadas de la ciudad, sino que afecta también al propio centro urbano.

Pasamos después junto al monumento barroco; el santo sostenía a la nube, la nube al ángel, el ángel a otra nube, la otra nube a otro ángel; el cielo estaba más azul que por la mañana; [...] el calor no hacía más que aumentar la sensación de vacío polvoriento; la escultura estaba parada en medio de la plaza como un trozo de cielo desgajado que no puede volver a su sitio; en ese momento me dije que nosotros dos también habíamos sido arrojados a esta extraña plaza desierta con su parque y su restaurante, que habíamos sido arrojados aquí irremisiblemente; que nosotros dos también estamos desgajados de algún sitio; que imitamos inútilmente al cielo y a las alturas, que nadie se lo cree; que nuestras ideas y nuestras palabras trepan en vano hacia las alturas mientras que nuestros actos son tan bajos como la misma tierra. (Kundera 1984: 198)

De nuevo está presente en esta descripción la idea de la determinación, de la imposibilidad de ascenso del hombre caído (en desgracia).

Todo en la ciudad es pésimo: las instalaciones, los paisajes, los servicios. Así, el hotel donde se alojan Ludvik y Helena (Kundera 1984: 9-10), como el restaurante donde comen juntos: "Le dije que iríamos a comer a La Casa del Pueblo, que es un restaurante malo y, sin embargo, el mejor que hay en esta ciudad" (Kundera 1984: 198).

Pero a pesar de toda esta negatividad, en su ciudad natal se reencuentra con el pasado y con la música folklórica morava, una de las pasiones de su juventud, de modo que no le queda otro remedio que confesar su nostalgia del pasado.

[...] en ese momento estaba repleto de un entristecido amor; amor hacia este mundo al que había abandonado por completo años atrás, hacia un mundo lejano 
y pretérito, $[\ldots]$ un mundo que se confunde con la imagen de mi ciudad natal y con la imagen de mi madre [...] y de mi infancia. (Kundera 1984: 320)

Lo cual puede explicar, en parte, qué ataba a Milan Kundera a su país, para que tardase tanto en abandonarlo después de empezar a ser considerado persona non grata.

El caso de El libro de la risa y el olvido es diferente. Las pequeñas ciudades checas no están tan presentes como en La broma y la capital, Praga, cobra mayor protagonismo. También aparecen ciudades de la Europa occidental -recordemos que en la época en que Kundera escribe esta obra, ya vivía en Francia desde hacía varios años. Aquí, la visión de las ciudades checas no es tan negativa como en la novela anterior; sin embargo, es interesante el contraste y la relación que se establecen entre las ciudades de la Europa del Este y las del Oeste.

Desde la distancia, Kundera tiene más libertad para hablar de su tierra. Así, se permite ironizar en sus descripciones de la ciudad y de las personas que la gobiernan.

[...] y debajo de ellos estaba Praga con sus cafés llenos de poetas y sus prisiones llenas de traidores al pueblo y en el crematorio quemaban en ese preciso momento a una diputada socialista y a un surrealista, el humo subía hacia el cielo como un presagio feliz [...]. (Kundera 2003: 17)

Praga aparece constantemente vinculada a los acontecimientos históricos y, por lo tanto es el escenario donde se desarrollan estos hechos narrados por Milan Kundera -en muchos casos- en primera persona. Así, Praga es testigo de la "liberación" de 1948, cuando los comunistas toman el poder en Checoslovaquia; del endurecimiento del régimen comunista, de las persecuciones, del intento de apertura que supuso la Primavera de Praga y de la entrada de los tanques soviéticos en la capital en 1968.

Praga aparece descrita a través de una serie de epítetos nada favorables:

1) Praga es la ciudad del mal: "Praga es, como decía Max Brod, la ciudad del mal" (Kundera 2003: 234).

2) Es la ciudad de la tristeza: “[...] estaba sentado un día del año 1971 en mi piso de la calle Bartolomejska. Mirábamos desde la ventana las cúpulas de las torres del castillo de Hradcany y estábamos tristes" (Kundera 2003: 235).

3) Praga es la ciudad de la decepción, del desengaño; es el espacio donde las ilusiones de los personajes se transforman en desencanto (Kundera 2003: 187189).

4) Pero Praga es, sobre todo lo anterior, la ciudad del olvido, uno de los leitmotivs que atraviesan el libro. "Praga es una ciudad sin memoria" (Kundera 2003: 235), cuyos dirigentes se han preocupado especialmente por borrar su pasado, las huellas de la historia.

[Gustav Husak] el séptimo presidente de mi patria es el llamado presidente del olvido. Los rusos lo instalaron en el poder en 1969. Desde 1621 no ha soportado 
la historia de la nación checa una masacre de la cultura como la de su gobierno. [...] la lucha contra la oposición política ha sido más bien una excusa y una oportunidad que los rusos han aprovechado para alcanzar por medio de su virrey algo mucho más esencial. (Kundera 2003: 235)

El olvido comienza por lo más esencial -los nombres de las calles y los monumentos, por ejemplo-y alcanza niveles más altos de una manera sutil: "Considero muy elocuente en este sentido que Husak haya expulsado de las universidades y los institutos científicos a ciento cuarenta y cinco historiadores checos" (Kundera 2003: 235).

La calle en la que nació Tamina se llamaba Schwerin. Eso fue durante la guerra y Praga estaba ocupada por los alemanes. Su padre nació en la avenida Cernokostelecka. Eso fue durante el imperio austro-húngaro. La madre de Tamina fue a vivir con su marido a la avenida del Mariscal Foche. Eso fue después de la primera guerra mundial. Tamina pasó su infancia en la avenida de Stalin y su marido se la llevó a su nueva casa de la avenida de Vinohrady. Y mientras tanto era siempre la misma calle, sólo que le cambiaban de nombre, le lavaban el cerebro para idiotizarla.

Por calles que no saben cómo se llaman vagan los fantasmas de las estatuas derruidas. Las destruía la reforma checa, las destruía la contrarreforma austríaca, las destruía la república checoslovaca, las destruyeron los comunistas y han sido derruidas hasta las estatuas de Stalin. En el lugar de todas aquellas estatuas derruidas crecen hoy por toda Bohemia miles de estatuas de Lenin, crecen como la hierba entre las ruinas, como melancólicas flores del olvido. (Kundera 2003: 234)

Por el contrario, las ciudades occidentales que se mencionan en El libro de la risa y el olvido, no identificadas en la mayoría de los casos, son las ciudades de la risa, de la libertad y de la subversión de los valores establecidos, subversión que, en ocasiones, lleva a los personajes a actuar de manera absurda.

Las pocas ciudades de la Europa capitalista claramente nombradas e identificadas tienen que ver directamente con la biografía de Kundera, como Rennes, la primera ciudad en la que se instaló tras huir de su país (Kundera 2003: 192) o París, donde el escritor checo reside desde 1980.

Para Kundera, su residencia en Francia es un refugio, una especie de atalaya desde la que observar desde la distancia el pasado y el presente de su patria: "Lo veo desde la distancia de mi torre francesa" (Kundera 2003: 229). Él mismo ha explicado, en una entrevista concedida a Philip Roth, que en esta obra los acontecimientos que suceden en Praga son vistos "a través de la mirada occidental" (Roth 2001: 92).

En El libro de la risa y el olvido queda reflejada -a través de diferentes personajes históricos y ficticios, así como en la experiencia del propio autor- la situación de todos aquellos checos considerados enemigos del régimen: cómo su posición es cada vez más insegura, "[...] desahuciados por el propio movimiento en el que creían" (Kundera 1985: 133), en una progresiva expulsión del círculo -como metafóricamente define Kundera- hasta la caída final.

Yo también bailé la rueda. Era la primavera de 1948, los comunistas acababan de triunfar en mi país, los ministros socialistas y cristianos huyeron al extranjero y 
yo me cogía de la mano o de los hombros con otros estudiantes comunistas [...]. Luego un día dije algo que no tenía que haber dicho, me expulsaron del partido y tuve que salirme de la rueda.

Entonces tomé conciencia del significado mágico del círculo. Si nos alejamos de la fila, podemos volver a entrar en ella. La fila es una formación abierta. Pero el círculo se cierra y no hay regreso posible. No es casual que los planetas se muevan en círculo y que cuando una piedra se desprende de ellos sea arrastrada inexorablemente hacia afuera por la fuerza centrífuga. Igual que el meteorito despedido volé yo también del círculo y sigo volando hasta hoy. (Kundera 2003: 104-105)

La inseguridad se acentúa porque "uno nunca sabe cuándo va a empezar a gritar el Estado que tal o cual palabra lo subvierte" (Kundera 2003: 10). Es por eso que todos los "intelectuales" - pues la palabra "intelectual" se había convertido en un insulto, así como "cosmopolita" o "individualista"- se sienten constantemente amenazados.

Poco a poco, aquellos considerados "enemigos" emigran o quedan desempleados o se les obliga a trabajar como obreros en fábricas y minas. El caso es que paulatinamente son borrados, condenados al olvido.

Los que están en la emigración (son cerca de ciento veinte mil), los que han sido acallados y echados de sus trabajos (son medio millón), desaparecen como una procesión que se aleja en medio de la niebla, no se les ve, se les olvida. (Kundera 2003: 45)

Cuando el propio Kundera se ve en esta situación, cuando los rusos -en 1968le echan del trabajo "(como a otros millares y millares de checos) sin que nadie tuviera derecho a dar[le] otro empleo" (Kundera 2003: 94), sus amigos le ofrecen publicar artículos en periódicos y revistas o escribir guiones de cine, siempre firmados con seudónimo. Kundera escribe entonces una sección de astrología en una revista juvenil durante algún tiempo, hasta que el engaño es descubierto. Entonces se da cuenta de que no puede vivir entre amigos, familiares y personas queridas sin ponerlas en peligro; "[...] por lo tanto no tenía otra alternativa que irme de mi país" (Kundera 2003: 117). Él mismo explica cómo, algunos años después de que los rusos ocupasen el país y de que sus libros fueran retirados de todas las bibliotecas públicas, abandonó Checoslovaquia al volante de su propio coche, conduciendo rumbo a occidente.

La primera ciudad de la Europa occidental en que se instala es Rennes, en cuya universidad impartió clases de literatura comparada hasta 1980. Sin embargo, y a pesar de la lejanía, no olvida su pasado y sigue observando -a dos mil kilómetros de distancia- lo que sucede en su país.

Los veo desde una distancia de dos mil kilómetros. Estamos en el otoño de 1977, mi país dormita desde hace ya ocho años, abrazado dulce y firmemente por el imperio ruso, [...] y mis libros, retirados de toas las bibliotecas públicas, han sido encerrados en algún sótano estatal. Esperé algunos años más y luego me senté al volante del coche y me fui lo más hacia Occidente que pude, hasta la ciudad bretona de Rennes, donde encontré, nada más llegar, un piso en la planta más alta del 
edificio más alto. Al día siguiente por la mañana, cuando me despertó el sol, comprendí que las amplias ventanas estaban orientadas hacia el este, hacia Praga. (Kundera 2003: 192)

En este caso Praga y todo su país aparecen como "dormidos", aislados del resto del mundo gracias al abrazo ruso.

Milan Kundera no quiso regresar a su país tras la caída del telón de acero. Recientemente, en 2007, se le otorgó el Premio Nacional Checo de Literatura, de cuya entrega se ausentó aduciendo problemas de salud (AFP 2007).

\section{BIBLIOGRAFÍA}

AFP (2007): "Premio a Milan Kundera provoca controversia en República Checa" [en línea]. El universo, 27/10/2007. En: http://www.eluniverso.com/2007/10/27/0001/1064/B90 B68AC3ED44AF29152DE5AF74822D9.html [Consulta: mayo de 2010].

AUGÉ, Marc (1992): Non-lieux: introduction à une anthropologie de la surmodernité. Paris: Éditions du Seuil.

BLOOM, Harold (2003): Milan Kundera. Pennsylvania: Chelsea House Publishers.

KUNDERA, Milan (1984): La broma. Barcelona: Seix Barral.

- (2003): El libro de la risa y el olvido. Barcelona: Seix Barral.

MUNIIZ-HUBERMAN, Angelina (1999): El canto del peregrino: hacia una poética del exilio. Barcelona: Associació d'Idees-GEXEL / Universidad Nacional Autónoma de México.

NUÑEZ, Gonzalo (2007): "Reconciliación de Milan Kundera con los checos da otro paso" [en línea]. Radio Praha, 24/10/2007. En: http://www.radio.cz/es/rubrica/personalidades/reconciliacion-de-milan-kundera-con-los-checos-da-otro-paso [Consulta: mayo de 2010].

RADIO PRAHA (1998): "El presidente Havel concluyó visita oficial de cuatro días a Gran Bretaña" [en línea]. Radio Praha, 23/10/1998. En: http://archiv.radio.cz/espanol/comentarios/23-10-98.html [Consulta: mayo de 2010].

ROTH, Philip (2001): Shop talk: a writer and his colleagues and their work. New York: Houghton Mifflin Company. 